\title{
WORK STRESS AMONG FULL-TIME EXTERNAL EMPLOYEE ASSISTANCE PROFESSIONALS: THEORY DEVELOPMENT
}

\author{
Shruti Jayakumar \\ Research Scholar \\ Department of Psychology \\ Jain University \\ Bangalore
}

\author{
Dr. Pooja Varma \\ Assistant Professor \\ Department of Psychology \\ Jain University \\ Bangalore
}

\begin{abstract}
Full-Time External Employee Assistance Professionals (EAP) refer to employees working round the clock in thirdparty firms that provide numerous confidential and preventive initiatives to corporate organizations with objectives of improving employee and organizational well-being. Research studies in the past highlighted the benefits of existing full-time external professionals extending employee assistance services to several MNCs such as reduced individual job-related stress and enhanced organizational productivity. There has been a paucity of literature in exploring the various workplace stressors faced by these professionals themselves during the process of providing these services to their external client companies. Nevertheless, studies examined the challenges faced by them, however, the dearth of researches inspired the investigator to explore the need for interventions that can be provided to full-time external consultants in managing their own work stress in a rotational shift -based job scenario. In addition to these research gaps, current literature regarding the average retention period of full-time external employee assistance professionals in India lasting until two to three years elucidates a challenge in terms of a wide gap that exists between the growing need of these services by corporate organizations in this country and the persistent ability of the employers of full-time external employee assistance professionals to meet their increasing client demands. Therefore, this concept paper highlights the necessity to develop an indigenous theory of work stress among full-time external employee assistance professionals to give impetus for further research regarding in-house stress management interventions which will have
\end{abstract}

positive consequences for individuals and corporate organizations at large.

Keywords- Full-Time External Employee Assistance Professionals, Work Stress, Indigenous theory of work stress

\section{INTRODUCTION}

Work stress refers to a pattern of responses that are displayed by individuals when there is an incongruence between employee skills, employee abilities and the job demands, pressures expected by the employers which can occur due to poor work organization, poor work design and lack of control ( Maullick, 2017), Though work stress is considered to be a usual process of every occupation in the current scenario, there has been a dearth of literature regarding the process, causes and consequences if work -related stress among professionals that cater to the well-being of employees especially, employee assistance professionals.

According to John Newstrom (2012), every employee at the workplace goes through the process of stress according to the stages proposed by Hand Selye. Thus, in the phase of stressful job demands, employees go through the alarm stage whereby numerous types of physiological responses can occur such as a rapid breathing rate, a rapid heart rate, sweaty palms, severe body pains, headache etc. due to which his or her energy level as well as the existing coping mechanisms tend to reduce due to initial shock faced by the individual in response to the stressful work-related demands. However, when an employee moves on to the resistance stage, he or she is more equipped with various behavioural, biochemical and psychological " $=$ mechanisms to manage the stressful situations that they are likely to encounter in their workplace by enabling the employee to focus on the origin of the stressful situation. However, in the process of attempting to trace the workplace stressor, certain individuals can 


\section{International Journal of Engineering Applied Sciences and Technology, 2020 Vol. 4, Issue 9, ISSN No. 2455-2143, Pages 416-420 \\ Published Online January 2020 in IJEAST (http://www.ijeast.com)}

experience frequent cold or other types of immune system related illnesses since the body's immune system gets negatively affected at this stage. According to Selye, in case the source of the workplace stress continues to persist for a longer period, the employee can reach the third or final stage of exhaustion whereby the individual has utilized all his or her resources to the maximum thereby reaching a stage of burnout, particularly, job burnout

The term job burnout refers to a phase characterized by three components namely emotional exhaustion, cynicism and reduced professional efficacy. Emotional exhaustion is marked by lethargy, tiredness and inability to express empathy as well as compassion for other fellow individuals. Sometimes emotional exhaustion is also referred to as compassion fatigue. Cynicism or Depersonalization on the other hand refers to an attitude of indifference displayed by employees towards their job and people in their work environment. It is at this phase that individuals become emotionally detached from employees as well as external clients. Sometimes cynicism is also expressed in an indirect manner when employees blindly follow the rigid rules and regulations established by their organization without assessing and contemplating the needs of the clients to arrive at solutions. The final component of the job burnout process is reduced professional efficacy or reduced personal accomplishment where employees no longer feel confident in their job-related tasks since they feel that their efforts and hard work on the job does not create any value or impact to the overall growth of the organization.

Though research studies conducted in Western countries indicate a high degree of all three components of the job burnout among helping professions, recent research studies conducted in the Indian Scenario have observed this phenomenon among management executives as well with certain contradictions. For instance, they observed that Indian management executives did not suffer from reduced professional efficacy but rather from being having an extreme sense of achievement motivation which could result in ambiguity, dissatisfaction, powerlessness and physical exhaustion. Other effects of burnout included absenteeism, noncompliance, low productivity, alcoholism, lack of teamwork and interpersonal team conflict (Shane, McGlinow \& Sharma, 2012).

According to Sharma (2012), workplace Stressors can be categorized into four main domains such as interpersonal Stressors, role-related Stressors, organizational Stressors and work-nonwork stressors.

Interpersonal Stressors: workplace violence, psychological harassment or unwanted conduct as well as comments that negatively affect an employee 's psychological and physical integrity and sexual harassment in the workplace are interpersonal Stressors that can deteriorate an individual 's Interpersonal and interpersonal well-being in the workplace.

Role-related Stressors: These stressors include role conflict and role ambiguity. While role conflict includes a sense of incongruence of an employee 's job responsibilities pertaining to his or her role in the organization, role ambiguity refers to a lack of clarity regarding the expected work-related outcomes from employees. Work overload and low task control are two other types of role-related stressors. While work overload refers to employees working for prolonged hours in their office environment, low task control refers to the challenges in managing the pace of work as per the employee's level of attention span, energy and other emotional resources.

Organizational and physical environment stressors: These stressors include performance-based layoffs, business restructuring, reduced job security due to witnessing employees being laid off, additional workloads due to reduced staff size, excessive noise, poor lighting and dangerous work environment.

Work and Non- Work Stressors: The three types of work and non-work stressors include time-based conflict, strain-based conflict and role behavior conflict. While time-based conflict and role-based conflict refer to conflicts that arise from attempting to balance work, family, other recreational activities and the stress that arises from when one personal aspect of life tends to spill over into the professional aspect of an employee 's life, role behavior conflict refers to a conflict when people are expected to act differently in their professional and personal spaces.

Work stress costs both the individual employees as well as the organization at large. While individual employees can suffer from a range of physiological consequences such as tension headaches, hypertension, muscle pain, back problems, anxiety, heart attacks, sleeplessness ; a range of psychological consequences such as mood swings, job dissatisfaction, lower organizational commitment and behavioural consequences such as absenteeism, presenteeism, disengagement, low productivity and team work; the impact of work stress on the organization includes a decline in organizational profits, low employee turnover, lower employee retention and the lacuna in identifying as well as channelizing the right talent pool to complete the assigned tasks in an organization ( McShane, Glinow \& Sharma, 2012) Despite the existence of literature regarding the prevalence of work stress among different occupations in India, yet work stress is an often a neglected aspect of well-being primarily among healthcare and wellness professions. According to a 


\section{International Journal of Engineering Applied Sciences and Technology, 2020 Vol. 4, Issue 9, ISSN No. 2455-2143, Pages 416-420 \\ Published Online January 2020 in IJEAST (http://www.ijeast.com)}

recent study among 72 employees belonging to different domains including the health and wellness sector across India revealed numerous causes and effects of workplace stress that are common and unique across male and female employees. Two main contributing factors of stress among male and female healthcare employees include excessive workload and organizational conflicts. The stressor of excessive workload has been demonstrated by various research studies conducted among doctors and nurses in India. A research study conducted among 140 healthcare workers in Nelamangla, Bangalore to examine the stressors and the level of stress faced by these workers revealed that some of the reasons reported by the participants as Antecedents of stress include long working hours beyond the stipulated time, lack of clarity and conflicts regarding the expected job roles/ demands and the lack of appreciation, rewards and values given by authority, coworkers and authority in managing patients ( Sagar, Ranganatha, Ahmed \& Shanmugapriya, 2017). Similar results were also demonstrated among 55 healthcare workers including dieticians in various parts of Thiruvarur in Tamil Nadu whereby the data collected from a semistructured questionnaire and analyzed through various statistical tools such as descriptive tests and chi-square tests reveal that work overload, time pressure and managing terminally ill patients were major sources of stress for these healthcare workers (Karthikeyan \& Babu, 2015). Besides the two factors of excessive workload and organizational conflicts, lack of job satisfaction is another major antecedent of stress as elucidated in the results of a cross-sectional research study conducted among dieticians and nurses in Karnataka, Kerala, Maharashtra as well as Tamil Nadu which indicate a loss of interest and a lack of job satisfaction as the primary source of workplace stress (Anasuydevi, Kanjana, Kavitha \& Brinda Devi, 2013).

Though some of the causes tend to be commonly experienced by both male and female employees in the health and wellness industry, a few research studies have indicated that while men manifest stress due to excessive workload, lack of job satisfaction and organizational conflicts through frustration and lack of attention, women respond to these stressors in the form of exhaustion. Though lifestyle imbalance is a common effect of stress among both male and female employees in the health and wellness sector as observed among 84 doctors and 114 nursing staff and dieticians in a tertiary care hospital in Kancheepuram, Tamil Nadu through involvement in maladaptive lifestyle patterns such as sleep deprivation, frequent skipping of meals, over-eating, smoking and regular consumption of alcohol to cope with stressful work environments, gender differences exist in emotional as well as behavioural imbalance, with male employees experiencing more emotional problems and female employees experiencing more behavioural problems (Narayanan et al.(2016, 2017). In addition to differences in lifestyle problems, it was inferred that male employees tend to experience headaches and muscular pains more often because of workplace stress and women employees experience more obesity, diabetes, hypertension, weight gain as physical outcomes of stress. However, low emotional regulation and coping mechanisms were associated among both male rather than female health and wellness professionals since female employees tend to share their sources of stress with their colleagues more than their male counterparts (Pattnaik \& Mishra, 2017).

\section{NEED FOR THE STUDY}

Though a plethora of research studies have been documented regarding the causes, consequences and prevalence of work stress among doctors, nurses, dieticians and other healthcare professionals, there has been a paucity of literature regarding the concept of stress, it's predictors and outcomes among employee assistance professionals especially Fulltime external employee assistance professionals.

Majority of the research literature in Western countries and in India regarding employee assistance programs have been related to the prevalence of the different models of employee assistance programs, challenges in accessing this program and screening clients availing this program through scientific programs, lack of awareness and promotion of these services, lack of uniformity regarding the model of delivery of these services and mixed results regarding the impact of the employee assistance program on employee well-being (Mollenhaeur et al. ( 2015, 2017, 2018). However, there has been a lacuna of research knowledge with respect to the challenges, the conceptualization of stress in its entirety from the perspectives of the professionals providing employee assistance programs especially in India since employee assistance program is a relatively new phenomenon in India compared to Western Countries (Francis, 2012). Though a few research studies conducted among both full-time and part-time employee assistance professionals in Canada and Australia regarding certain contributors of stress such as following the capped limit of the number of sessions each client can avail depending upon their organization and the lack of clarity regarding the payment as well as submission of counselling notes, compassion fatigue or the inability to feel empathy towards clients owing to high levels of stress, similar or contradictory findings in the Indian Context among these professionals are a paucity in the existing review of literature in India (Jacobson et al. ( 2010, 2012). 


\section{International Journal of Engineering Applied Sciences and Technology, 2020 Vol. 4, Issue 9, ISSN No. 2455-2143, Pages 416-420 \\ Published Online January 2020 in IJEAST (http://www.ijeast.com)}

In addition to the reasons mentioned above, another primary reason behind the need to develop a theory of work stress among full-time external employee assistance professionals is owing to the research finding that the average retention rate of full-time external employee assistance professionals in India ranging between two and three years (Gupta, 2017). Thus, it becomes imperative to explore the workplace challenges faced by these full-time external employee assistance professionals since they provide employee assistance services or numerous short-term preventive counselling, legal, financial, medical, childcare and elder care support to employees and their family members round the clock. In addition to providing support in the areas mentioned above, full-time employee assistance professionals (EAP Professionals) also involve in conducting employee-well-being training programs and awareness programs about employee assistance services.

Therefore, by gaining insights into the work-related demands faced by these professionals can aid in increasing their overall well-being and increasing their work retention period by developing interventions to cope with these demands that are similar or different from a few interventions already established for healthcare workers in the West to manage their lifestyle stressors of hypertension, weight loss or gain in the form of interpersonal health coaching (Francis, et al. (2012. 2019).

Therefore, through the process of understanding the meaning, causes and consequences of work stress faced by these full-time external employee assistance professionals as well as developing a theory, various measures can be undertaken to ensure the overall well-being of these professionals since the well-being of these professionals is directly related to the quality of employee assistance services provided by them to the employees of their client companies. From the perspective of the employers of these professionals, this in turn will boost their morale in meeting and assuring client organizations regarding the timely and effective delivery of employee assistance services thereby contributing to the economic growth of their respective firms (Francis, 2012).

\section{PROPOSED METHODOLOGICAL FRAMEWORK}

The purpose mentioned in this concept paper is to develop an indigenous theory of work stress for fulltime external employee assistance professionals working in third-party firms. Thus, the proposed Framework for implementing this aim is to conduct a qualitative -based research study using Charmaz's Constructivist Grounded Theoretical framework. Constructivist Grounded theory is the process of developing a theory through a collaboration between the participants and the researcher during the process of construing the theory of work stress through the application of abductive reasoning. Initially, the data would be collected and analyzed simultaneously from the sample through the following research questions till there is a saturation of common and specific hypotheses that can be tested further either through the researcher 's preexisting knowledge about the topic or through suitable empirical methods depending upon the cases inferred during this research technique.

Broad Research Questions based on the Proposed Methodological Framework

1. How are the different factors specific to Full-time External Employee Assistance Professionals contributing to our understanding of the meaning of work stress?

2. How are the different processes specific to Full-time external employee assistance professionals contributing to our understanding of the meaning of work stress?

3. How are the different actions specific to Full-time external employee assistance professionals contributing to our understanding of the meaning of work stress?

4. How are the different consequences specific to Fulltime external employee assistance professionals contributing to our understanding of the meaning of work stress?

5. How are the perceptions of full-time external employee assistance professionals contributing to our understanding of the meaning of work stress?

\section{CONCLUSION}

This paper aims at highlighting the importance of developing an indigenous theory of work stress among full-time external employee assistance professionals. The outline of this paper begins with a general introduction to the meaning, process and impact of work stress on both individuals and organizations especially among male and female employees in the health and wellness industry in India through existing research studies. The gaps emerged from the current review of literature regarding this topic have been mentioned as reasons under the rationale behind conducting this qualitative research study through Charmaz (2014) Constructivist Grounded theory though the application of abductive reasoning related to the broad research questions mentioned above. While the theoretical implications of this research study include contributing to the lacuna of knowledge related to professionals providing employee assistance services in India, the practical implication of conducting this qualitative research study include enhancing the well-being of these professionals through the development of stress management 
interventions to enhance the overall well-being of the employees as well as their respective organizations.

\section{REFERENCES}

Azzone, Vanessa. (2009). Workplace Stress, Organizational Factors and EAP Utilization. Journal of Workplace Behavioural Health, 344-356.

Csiernik, Rick. (2012). The Glass is Filling: An Examination of Employee Assistance Program Evaluations in the First Decade of the New Millenium. Journal of Workplace Behavioural Health, 334-355.

Csiernik, Rick. (2016). From the Outside Looking Out: A Qualitative Examination of the Experiences of Canadian External EAP Providers. EASNA Research Notes.

Francis, Abraham. (2012). Employee Assistance Programme in Industrial Organization (Social Work Concepts and Practices). New Delhi: Autopress Global Network.

Grounded Theory. (n.d.). Retrieved from http://www.health.herts.ac.uk/immunolog y/Web\%20programme\%20-

\%20Researchhealthprofessionals/grounde d_theory.html

Krekel, Christian (2013).Employee Wellness Program Outcomes: A case study. Journal of Workplace Behavioural Health, 28 (1) : 46-31.

Maiden, Paul. (2017). Global Perspectives of Employee Assistance Programmes. New York: Taylor and Francis Group.

McShane, Steven., Glinow, Mary., \& Sharma, Radha. (2012). Organizational Behaviour: Emerging Knowledge and Practice for the real world. New Delhi: Tata mcGraw Hill Education Private Limited.

Newstrom, John (2012). Organizational Behaviour: Human Behaviour at Work. New Delhi: Tata Mc-Graw Hill Publishing Company Limited.

Pathak, Sonal. (2017). Disparity in Stresses among Males and Females in Outsourcing Industry. Research Journal of Social Science and Management.

Sharma, Manish \& Negi, Anita (2018, January 15). Corporate Wellness can save India Inc. revenue to US \$20bln: ASSOCHAM. Retrieved from ASSOCHAM: https://www.assocham.org

Steger, Julia. (2015). Employee Assistance Programmes: Factors for Organizations to Consider. Nordest, Germany: Grin Verlag. 